University of New Hampshire

University of New Hampshire Scholars' Repository

$7-2005$

\title{
National Estimates of Children Missing Involuntarily or for Benign Reasons.
}

Andrea J. Sedlack

Westat, Inc.

David Finkelhor

University of New Hampshire - Main Campus, David.Finkelhor@unh.edu

Heather Hammer

Temple University

Follow this and additional works at: https://scholars.unh.edu/ccrc

Part of the Criminology Commons

\section{Recommended Citation}

Andrea J. Sedlak, David Finkelhor, \& Heather Hammer. National Estimates of Children Missing Involuntarily, or for Benign Reasons. Juvenile Justice Bulletin - NCJ206180 (pgs. 1-12). Washington, DC: US Government Printing Office.

This Article is brought to you for free and open access by the Research Institutes, Centers and Programs at University of New Hampshire Scholars' Repository. It has been accepted for inclusion in Crimes Against Children Research Center by an authorized administrator of University of New Hampshire Scholars' Repository. For more information, please contact Scholarly.Communication@unh.edu. 
U.S. Department of Justice

Office of Justice Programs

Office of Juvenile Justice and Delinquency Prevention
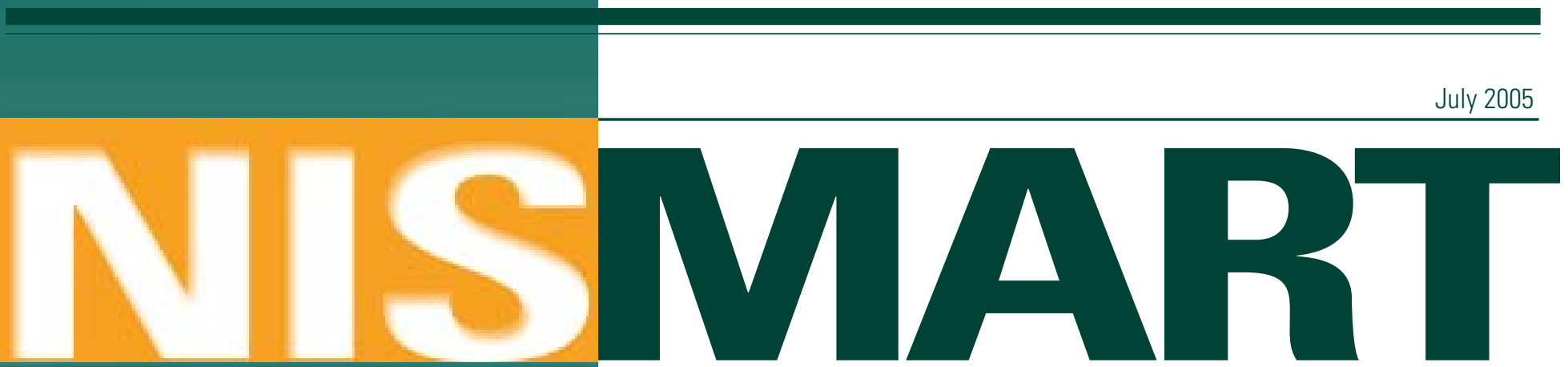

National Incidence Studies of Mi ssing, Abducted, Runaway, and Thrownaway Children

Office of Justice Programs

Partnerships for Safer Communities

www.ojp.usdoj.gov

\section{National Estimates of Children Missing Involuntarily or for Benign Reasons}

\author{
By Andrea J. Sedlak, David Finkelhor, and \\ Heather Hammer
}

The words "missing child" call to mind tragic and frightening kidnappings reported in the national news. But a child can be missing for many reasons, and the problem of missing children is far more complex than the headlines suggest. Getting a clear picture of how many children become missing - and why-is an important step in addressing the problem. This series of Bulletins provides that clear picture by summarizing findings from the Second National Incidence Studies of Missing, Abducted, Runaway, and Thrownaway Children (NISMART-2). The series offers national estimates of missing children based on surveys of households, juvenile residential facilities, and law enforcement agencies. It also presents statistical profiles of these children, including their demographic characteristics and the circumstances of their disappearance.

This Bulletin provides information on the numbers and characteristics of two groups of children not frequently recognized in the literature on missing children: those involuntarily missing because they were lost, injured, or stranded and those missing for benign reasons. The estimates reported in this Bulletin are derived from two components of the Second National Incidence Studies of Missing, Abducted, Runaway, and Thrownaway Children (NISMART-2): the National Household Survey of Adult Caretakers and the National Household 


\section{NISMART-2 Definitions of Episode Types}

Missing Involuntary, Lost, or Injured (MILI)

A missing involuntary, lost, or injured episode occurs when a child's whereabouts are unknown to the child's caretaker, who either contacts law enforcement or a missing children's agency to locate the missing child or becomes alarmed for at least 1 hour and tries to locate the child, and one of the following conditions applies: (1) the child was trying to get home or make contact with the caretaker but was unable to do so because the child was lost, stranded, or injured (defined as physical harm that required medical attention or resulted in injuries that were evident the next day, e.g., cuts, bruises, or sprains); or (2) the child was too young to know how to return home or make contact with the caretaker.

\section{Missing Benign Explanation (MBE)}

A missing benign explanation episode occurs when a child's whereabouts are unknown to the child's caretaker, who either contacts law enforcement or a missing children's agency to locate the missing child or (1) becomes alarmed for at least an hour, (2) tries to locate the child, and (3) contacts the police about the episode for any reason, as long as the child was not lost, injured, abducted, victimized, or classified as runaway/thrownaway.

Survey of Youth. These surveys were conducted during 1999 and reflect the experiences of children in the United States over a 12-month period. Because the vast majority of cases were concentrated in 1999, the annual period the Bulletin refers to is 1999.

\section{Key Findings}

- In 1999, an estimated 204,500 children were involuntarily missing from their caretakers because they were lost, injured, or stranded; 68,100 of these children were reported to authorities (for assistance in locating them). ${ }^{1}$

- An estimated 43,700 children were missing because they were injured; 10,200 of these children were reported to authorities (for assistance in locating them).

- An estimated 340,500 children missing from their caretakers and reported to authorities for purposes of being located were missing as a result of benign circumstances and miscommunications that resulted in no harm to the child. These children constituted 43 percent of the children reported missing in all categories.
Children missing involuntarily because they were lost or injured were disproportionately white, male, and older. They disappeared most frequently in wooded areas or parks and from the company of their caretakers.

- Children missing as a result of benign circumstances and miscommunications were disproportionately teenagers who failed to come home or were gone longer than expected.

\section{Conceptualizing the Problem}

Conducted in 1988, the First National Incidence Studies of Missing, Abducted, Runaway, and Thrownaway Children, NISMART-1 (Finkelhor, Hotaling, and Sedlak, 1990) brought attention to a number of missing children who could not be classified as "abducted," "runaway," or "thrownaway." These children were classified as "lost, injured, and otherwise missing" in NISMART-1. Based on that study, the designers of NISMART-2 distinguished two subsets of missing children within this group: (1) children who were involuntarily missing and in potential danger because they became lost, injured, or stranded; and (2) children who were missing for benign reasons such as miscommunications and mistaken expectations.

The notion that children become missing because they get lost and cannot make their way back to their caretaker (for example, in a wilderness environment) is readily understood. However, a more serious reason that could prevent children from making their way back to their caretaker or home is an injury that impedes their mobility, such as a broken leg or a fall that renders them unconscious. Sometimes the need for immediate emergency medical attention requires taking these children to the hospital without notifying their families. In NISMART-2, these children are classified together into a new category called "missing involuntary, lost, or injured" (MILI).

Children missing because of a miscommunication or mistaken expectation are usually not in serious danger, despite the anxiety their absence causes their caretakers. NISMART-2 classified such situations as "missing benign explanation" (MBE). Classifying a child as "missing" for benign reasons is a new concept in the missing children field and therefore merits additional discussion. Today's complex world, where family members have hectic schedules and often are out of touch with one another for large parts of any given day, presents many opportunities 
for children to become missing for benign reasons. Unforeseeable circumstances (e.g., a flat tire, missing a ride, or helping a friend) can cause a child to be late for an appointment or arrival home. Miscommunications also occur among family members (e.g., the father picks up the child, not knowing that the mother planned to do so an hour later). Caretakers and children can have different expectations (e.g., a teenager may think it is alright to stay out an hour or two past curfew without calling or leaving a note, when this is not the caretaker's view). In such circumstances, caretakers can become alarmed to the point of calling the police. However, the hallmark of these episodes is that the child was not harmed, lost, or stranded and did not qualify for any other category of episode that the NISMART-2 study targeted (i.e., nonfamily abductions, family abductions, and runaway/ thrownaway episodes).

The NISMART-2 definition of "missing" extended beyond the caretaker's lack of knowledge about where the child was. Parents frequently do not know exactly where their children are, especially older children, and may regard this as normal. To classify a child as "missing," the study also required either that the caretaker had contacted law enforcement or a missing children's agency to locate the child or that the child's unknown whereabouts had caused the caretaker to be alarmed for at least 1 hour and to look for the child. Classification as an MBE episode required caretaker contact with law enforcement or a missing children's agency in all cases. The purpose of the contact could be to report the child as missing, to recover the child from a known location, or any other reason related to the episode, as long as the child was not lost, injured, abducted, victimized, or classified as runaway/ thrownaway. See the sidebar on page 4 for examples of MILI and MBE episodes.

\section{Methodology}

MILI and MBE estimates are based on the NISMART-2 National Household Surveys of Adult Caretakers and Youth. The surveys were conducted during 1999, using computer-assisted telephone interviewing methodology to collect information from a national probability sample of households. Some 16,111 interviews were completed with an adult primary caretaker, resulting in an 80percent cooperation rate among eligible households with children and a 61-percent response rate. The number of youth that adult caretakers in the Household Survey sample identified was 31,787 . Each primary caretaker who completed an interview was asked for permission to interview a randomly selected member of the household between the ages of 10 and 18. Permission was obtained for 60 percent of the selected youth, yielding 5,015 interviews and a 95-percent cooperation rate among the youth whose caretakers granted permission to conduct an interview. Youth and adult interview data were weighted to reflect the census-based population of children.

The Household Surveys were designed to screen for potentially countable missing child episodes, to collect demographic information about the household and its members, to conduct indepth followup interviews specific to each type of missing child episode being studied, and to collect information about any actual or attempted sexual assaults that may have occurred during an episode. The types of episodes studied were family abductions; nonfamily abductions; runaway/thrownaway episodes; episodes that involved children who were involuntarily missing because they were lost, injured, or stranded; and episodes that involved children who were missing for a benign reason (e.g., a miscommunication between parent and child).

Adult caretakers and youth were screened with a set of 17 questions to determine their eligibility for an indepth followup interview pertaining to each type of missing child episode. The following three episode screening questions in the adult interviews led to the followup interview used to identify MILI and MBE episodes:

In the past 12 months, was there any time when this child was seriously hurt or injured and as a result didn't come home and you were concerned about where the child was?

Was there any time when you were concerned because you couldn't find this child or this child didn't come home?

Was there any time when this child became lost or you were unable to locate this child's whereabouts and you became alarmed and tried to find this child?

These questions applied to all children in the household. The responses to the followup interview in turn were used to determine if a missing child would be counted as MILI or MBE. The episode screening questions used in the youth interviews were essentially identical. 


\section{Examples of NISMART-2 Missing Involuntary, Lost, or Injured and Missing Benign Explanation Episodes}

\section{Missing Involuntary, Lost, or Injured}

A teacher put a 6-year-old boy on the wrong bus home on the first day of school. When the bus driver discovered the mistake, he returned the boy to the school, but the teacher had left. The only person still there was the secretary, who did not have a record of the boy's home phone number. The boy did not know how to contact his parents. During the interim, the parents were waiting at the bus stop, watching the buses come and go without dropping off their son. They became alarmed, called the school, and found that their son was unharmed and in the principal's office. The episode lasted an hour.

An 11-year-old girl was playing in a large wooded area behind her home and lost her direction. When the girl did not answer her mother's call for dinner, the mother became alarmed and called the police to help locate the missing child. While the police assisted in the search, the mother drove around the neighborhood asking if anyone had seen her daughter. It was 4 hours before the child found her way out of the woods behind a neighbor's house and was returned home safely.

A 16-year-old girl accompanied her friend to the doctor's office, and on the way home their car was involved in an accident. An ambulance transported the pair to the hospital, where they were examined and the girl was treated for a dislocation and a stress-induced asthma attack. The girl's mother became alarmed when she could not reach her daughter on her pager and called the girl's father and friends to find the girl. Nobody contacted the mother about her daughter's whereabouts until 5 hours after she became alarmed. The child was returned home 2 hours after she was located at the hospital. The episode lasted 7 hours.

A 2-year-old boy whose mother had taken him to a Christmas parade in a small community wandered into the crowd when she left him in the care of a neighbor while she went to use a restroom. The mother was alarmed and worried that her son might have been abducted. She contacted the police immediately to help locate her missing toddler. The police responded quickly and found the boy about a block away from where he disappeared. The episode lasted 10 minutes, and the child was returned to his mother unharmed.

A 14-year-old girl and her 10-year-old brother were hiking in a park with their father. With his permission, they went ahead on the trail and inadvertently got separated from him and lost. Losing sight of his children caused the father to be very alarmed, and he immediately backtracked the trails in search of them, asked any person he came across for help, and flagged down cars to ask where the trails ended. While he was searching for the children, they were trying to find him, and it took an hour before the father found his children unharmed.

\section{Missing Benign Explanation}

A 13-year-old boy skipped school without permission. The school called the police when the boy's absence was discovered, and both the police and the boy's frantic mother searched for him. At the time, the mother was convinced that her son was either injured or kidnapped because this had never happened before. The boy was gone for 3 hours before he returned home safely.

A 14-year-old boy was at his friend's house without permission. He failed to come home by his 11 p.m. curfew and did not call his parents. The boy's friend was someone his father knew but did not approve of. The father called all of the friends he expected his son to be with, and when he could not locate his son, he called the police to report the boy missing. The episode lasted 3 hours. During the interview, the father described the reason for the episode as a misunderstanding of what was expected. Apparently, the boy thought he did not need to come home by his curfew because there was no school the next day.

A 7-year-old boy was supposed to be watching television in the living room. His mother called him for dinner and discovered he was not there. Instead, the boy had gone outside to play and fallen asleep in the corner of the detached garage on their property. It was dark outside, and the parents searched for the boy with the assistance of their neighbors. When they could not find him, the neighbors called the police to assist in locating the missing child. The episode lasted 45 minutes.

A 1-year-old was out with her aunt, and when they were an hour late returning home, the baby's mother became alarmed and called the aunt and other family members to find her daughter. After 2 hours of trying to find the child, her grandparents called the police for help in locating her. Approximately 15-20 minutes after this call, the aunt returned the child home safely. During the interview, the mother explained that the episode was the result of unforeseen circumstances and the aunt's misunderstanding of what was expected.

A 15-year-old girl took a train to her friend's house right after school and spent the night there. The primary caretaker, who described herself as a friend of the child, thought that the girl was somewhere else and became alarmed when she did not call or come home later that night. The police were contacted to locate the missing child, who was found and returned home safely. The episode lasted 20 hours. 
MILI and MBE estimates reported in this Bulletin are unified estimates that combine the number of countable children who experienced these types of episodes as adult caretakers and youth described them in the Household Surveys. ${ }^{2}$ Any child is counted only once, even if the same type of episode was reported for the same child in both the adult and youth interviews. For details about the unification and weighting procedures and the variance estimation, see OJJDP's forthcoming NISMART-2 Household Survey Methodology Technical Report and NISMART-2 Unified Estimate Methodology Technical Report.

\section{Results}

In 1999, an estimated 204,500 children were involuntarily missing from their caretakers ("caretaker missing") because they were lost, injured, or stranded. Of these, 68,100 were reported missing to law enforcement or a missing children's agency (see table 1). The estimated number of caretaker missing children who were missing because they were injured was 43,700 (Sedlak et al., 2002). The MILI children constituted 16 percent of chil- dren missing from caretakers for any reason and 9 percent of all missing children reported to authorities.

Children missing from their caretakers in circumstances with benign explanations totaled 374,700 . The caretakers of an estimated 340,500 of these children reported them missing to authorities. ${ }^{3} \mathrm{MBE}$ children constituted 28 percent of children missing from their caretakers for any reason and 43 percent of all missing children reported to authorities (Sedlak et al., 2002).

Children younger than 12 were underrepresented in both categories (see table 2). Although children younger than 12 constituted 66 percent of the child population in 1999, they represented only 35 percent of MILI children and 36 percent of MBE children. Teenagers were overrepresented in both categories; however, the disproportionality was only significant for MBE episodes. Boys were overrepresented in the MILI category as compared with girls. Whites were overrepresented and blacks underrepresented in the MILI category. Further information will be needed to explain the significantly higher number of MBE children in the Midwest relative to their prevalence in the child population.

Table 1: Estimates of Missing Involuntary, Lost, or Injured and Missing Benign Explanation Children in the United States, 1999

\begin{tabular}{lccc} 
Type of Missing Child Episode & $\begin{array}{c}\text { Estimated } \\
\text { Number of Children }\end{array}$ & $\begin{array}{c}\mathbf{9 5 \%} \text { Confidence } \\
\text { Interval }\end{array}$ & Percent \\
\hline $\begin{array}{l}\text { Missing involuntary, lost, or injured } \\
\text { (MILI) }\end{array}$ & $\mathbf{2 0 4 , 5 0 0}$ & $\mathbf{1 3 1 , 3 0 0 - 2 7 7 , 8 0 0}$ & $\mathbf{1 0 0}$ \\
Caretaker missing & 204,500 & $131,300-277,800$ & 100 \\
$\quad$ Caretaker missing due to injury & $43,700^{\dagger}$ & $17,700-69,700^{\dagger}$ & $21^{\dagger, \S}$ \\
Reported missingף & 68,100 & $24,800-111,300$ & $33^{\S}$ \\
$\quad$ Reported missing due to injury & $10,200^{\dagger}$ & $200-20,200^{\dagger}$ & $5^{\dagger, \S}$ \\
Missing benign explanation (MBE) & 374,700 & $\mathbf{2 8 4 , 9 0 0 - 4 6 4 , 4 0 0}$ & $\mathbf{1 0 0}$ \\
Caretaker missing $^{\ddagger}$ & 374,700 & $284,900-464,400$ & 100 \\
$\quad$ Reported missing & 340,500 & $251,300-429,600$ & 91
\end{tabular}

Notes: The estimates provided here for the MILI category are marginally higher than estimates provided in a previous Bulletin, National Estimates of Missing Children: An Overview (Sedlak et al., 2002). The change resulted from the discovery of one child in the survey who had an experience that qualified as a MILI episode but who was inadvertently left out of that category because the child also had experienced another, separate missing child episode that came under a different category. The change does not affect the overall estimate of missing children. All estimates are rounded to the nearest 100.

$\dagger$ Estimate based on too few sample cases to be reliable.

‡ Child's whereabouts unknown to the parents or caretakers, causing them to become alarmed and try to locate the child. Includes children who were reported missing.

$\S$ Percent uses caretaker missing $(204,500)$ as the base.

ๆ Subset of caretaker missing children whose parents or caretakers reported them to the police or a missing children's agency for purposes of locating them 


\section{NISMART}

Table 2: Characteristics of Missing Involuntary, Lost, or Injured and Missing Benign Explanation Children in the United States, 1999

\begin{tabular}{|c|c|c|c|c|c|}
\hline \multirow[b]{2}{*}{ Characteristic } & \multicolumn{2}{|c|}{ MILI $(n=204,500)$} & \multicolumn{2}{|c|}{$\operatorname{MBE}(n=374,700)$} & \multirow{2}{*}{$\begin{array}{c}\text { Percent of } \\
\text { U.S. Child } \\
\text { Population } \\
(N=70,172,700)\end{array}$} \\
\hline & $\begin{array}{c}\text { Estimated } \\
\text { Number }\end{array}$ & Percent & $\begin{array}{c}\text { Estimated } \\
\text { Number }\end{array}$ & Percent & \\
\hline \multicolumn{6}{|l|}{ Age (years) } \\
\hline $0-2$ & $11,200^{\dagger}$ & $5^{* *}$ & $15,200^{\dagger}$ & $4^{+}$ & 15 \\
\hline $3-5$ & $9,500^{\dagger}$ & $5^{* *}$ & 41,500 & 11 & 17 \\
\hline $6-11$ & 51,900 & 25 & 77,100 & $21^{*}$ & 34 \\
\hline $12-14$ & 73,300 & 36 & 117,300 & $31 *$ & 17 \\
\hline $15-17$ & 58,600 & 29 & 123,600 & $33^{*}$ & 17 \\
\hline \multicolumn{6}{|l|}{ Gender } \\
\hline Male & 143,500 & $70^{*}$ & 229,700 & 61 & 51 \\
\hline Female & 61,000 & $30^{*}$ & 145,000 & 39 & 49 \\
\hline \multicolumn{6}{|l|}{ Race/ethnicity } \\
\hline White, non-Hispanic & 158,200 & $77^{*}$ & 215,100 & 57 & 65 \\
\hline Black, non-Hispanic & $14,800^{\dagger}$ & $7^{* *}$ & 68,100 & 18 & 15 \\
\hline Hispanic & $21,100^{\dagger}$ & $10^{\dagger}$ & 69,200 & 18 & 16 \\
\hline Other & $10,400^{\dagger}$ & $5^{\dagger}$ & $20,700^{\dagger}$ & $6^{\dagger}$ & 6 \\
\hline No information & - & - & $1,600^{\dagger}$ & $<1^{\dagger}$ & $-\S$ \\
\hline \multicolumn{6}{|l|}{ Region } \\
\hline Northeast & $32,600^{\dagger}$ & $16^{\dagger}$ & 59,800 & 16 & 18 \\
\hline Midwest & 40,000 & 20 & 134,200 & $36^{*}$ & 23 \\
\hline South & 63,100 & 31 & 102,300 & 27 & 35 \\
\hline West & 68,900 & 34 & 78,300 & 21 & 24 \\
\hline
\end{tabular}

Notes: $\mathrm{MILI}=$ missing involuntary, lost, or injured; $\mathrm{MBE}=$ missing benign explanation. Because all estimates have been rounded to the nearest integer, percentages may not sum to 100 .

* Statistically significant difference.

** Although the sample is too small to provide a reliable estimate of the exact percentage of missing children in this category, the difference between missing children and children in the general population is so great that it is statistically significant. That is, the information from the sample is sufficient to tell that the percentage for missing children is significantly below that for children in the general population in this group, although it is not sufficient to pinpoint the estimate itself reliably.

† Estimate based on too few sample cases to be reliable.

¥ Age, gender, and race for the U.S. population were based on the average monthly estimates of the population ages 0-17 years for 1999 (U.S. Census Bureau, 2000a). The regional distribution of the population was computed from state-by-state estimates of the population ages 0-17 as of July 1, 1999 (U.S. Census Bureau, 2000b).

$\S$ Category does not apply to the census data.

Most of the MILI and MBE children were gone less than 6 hours (table 3). Only 3 percent of MILI children and 5 percent of MBE children were gone for more than 1 day. MILI children disappeared primarily in wooded areas and parks and were often in the presence of their caretakers at the time they disappeared. In contrast, MBE children disappeared most often from a home other than their own. They did not disappear from their caretaker's presence as often as they simply failed to contact their caretakers or to come home when they were expected. 


\section{NISMART}

Table 3: Characteristics of Missing Involuntary, Lost, or Injured and Missing Benign Explanation Episodes in the United States, 1999

\begin{tabular}{|c|c|c|c|c|}
\hline \multirow[b]{2}{*}{$\begin{array}{l}\text { Episode } \\
\text { Characteristic }\end{array}$} & \multicolumn{2}{|c|}{ MILI $(n=204,500)$} & \multicolumn{2}{|c|}{$\operatorname{MBE}(n=374,700)$} \\
\hline & $\begin{array}{l}\text { Estimated } \\
\text { Number }\end{array}$ & Percent & $\begin{array}{l}\text { Estimated } \\
\text { Number }\end{array}$ & Percent \\
\hline \multicolumn{5}{|l|}{ Duration } \\
\hline Less than 1 hour & $17,200^{\dagger}$ & $8^{+}$ & 58,400 & 16 \\
\hline 1 hour to 6 hours & 158,200 & 77 & 256,900 & 69 \\
\hline 7 hours to less than 24 hours & $17,200^{+}$ & $8^{+}$ & 39,800 & 11 \\
\hline 24 hours to less than 1 week & $5,200^{\dagger}$ & $3^{+}$ & $12,300^{\dagger}$ & $3^{+}$ \\
\hline 1 week to less than 6 months & $600^{+}$ & $<1^{\dagger}$ & $7,200^{+}$ & $2^{+}$ \\
\hline Don't know & $6,100^{\dagger}$ & $3^{+}$ & - & - \\
\hline \multicolumn{5}{|l|}{ Location } \\
\hline Park or wooded area & 113,500 & 56 & $12,300^{\dagger}$ & $3^{+}$ \\
\hline School or daycare & 32,600 & 16 & $8,900^{\dagger}$ & $2^{\dagger}$ \\
\hline Shopping area or mall & $22,600^{\dagger}$ & $11^{\dagger}$ & $40,100^{\dagger}$ & $11^{\dagger}$ \\
\hline Street & $12,100^{\dagger}$ & $6^{+}$ & 34,600 & 9 \\
\hline Own home or yard & $9,700^{\dagger}$ & $5^{\dagger}$ & 46,000 & 12 \\
\hline Other home or yard & $6,700^{\dagger}$ & $3^{\dagger}$ & 125,700 & 34 \\
\hline Other public area & $4,500^{\dagger}$ & $2^{+}$ & $40,100^{\dagger}$ & $11^{\dagger}$ \\
\hline On vacation & $900^{\dagger}$ & $<1^{\dagger}$ & - & - \\
\hline Parent or caretaker's car & - & - & $29,600^{\dagger}$ & $8^{\dagger}$ \\
\hline On public transportation & - & - & $9,000^{+}$ & $2^{+}$ \\
\hline Other & $1,900^{\dagger}$ & $<1^{\dagger}$ & $24,600^{\dagger}$ & $7^{\dagger}$ \\
\hline Don't know & - & - & $3,800^{\dagger}$ & $1^{\dagger}$ \\
\hline \multicolumn{5}{|l|}{ How caretaker knew child was missing } \\
\hline $\begin{array}{l}\text { Child disappeared from caretaker's } \\
\text { supervision }\end{array}$ & 79,600 & 39 & 43,100 & 12 \\
\hline Child failed to come home & 58,300 & 29 & 122,800 & 33 \\
\hline Child was gone longer than expected & $18,600^{\dagger}$ & $9^{+}$ & 104,200 & 28 \\
\hline Child failed to call caretaker & $18,000^{\dagger}$ & $9^{\dagger}$ & 48,000 & 13 \\
\hline Other reason & $26,800^{\dagger}$ & $13^{+}$ & 56,600 & 15 \\
\hline No information & $3,300^{\dagger}$ & $2^{\dagger}$ & - & - \\
\hline \multicolumn{5}{|l|}{ Child was missing due to injury } \\
\hline Yes & $43,700^{\dagger}$ & $21^{\dagger}$ & $-{ }^{\ddagger}$ & $-\ddagger$ \\
\hline
\end{tabular}

Notes: MILI = missing involuntary, lost, or injured; MBE = missing benign explanation. Estimated numbers for episode characteristics may not sum to totals for episode type (MILI or MBE) because of rounding.

† Estimate based on too few sample cases to be reliable.

¥ Category does not apply to missing benign explanation children by definition. 
Table 4: Police Contact for Missing Involuntary, Lost, or Injured and Missing Benign Explanation Children in the United States, 1999

MILI $(n=204,500)$

Episode

Characteristic

\section{Police contact}

Yes

No

Reason for police contact ${ }^{\S}$

Locate missing child

Recover child from unknown location

Other reason

No information

Reason police were not contacted

Child was not gone long enough

Did not think police were needed

Child located without police assistance

School took care of problem

Don't know

$\begin{array}{ll}\text { Estimated } \\ \text { Number } & \text { Percent }\end{array}$

80,400

124,200

61

68,100

$6,200^{\dagger} \quad 8^{\dagger}$

$6,000^{\dagger} \quad 8$

$-$
$\operatorname{MBE}(n=374,700)$

Estimated

Number

Percent

374,700

100

$-{ }^{\ddagger}$

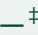

$340,500^{9}$

91

$21,700^{\dagger} \quad 6^{\dagger}$

$11,700^{\dagger}$

$800^{+}$

Notes: $\mathrm{MILI}=$ missing involuntary, lost, or injured; MBE = missing benign explanation. Estimated numbers for episode characteristics may not sum to totals for episode type (MILI or MBE) because of rounding.

† Estimate based on too few sample cases to be reliable.

‡ Does not apply to missing benign explanation children, as police contact was required by definition for this category.

$\S$ Percents for missing involuntary, lost, or injured children use 80,400 , the number of children in this category whose caretakers contacted the police, as the base. Percents for missing benign explanation children use 374,700 as the base, as police contact was required for inclusion in this category.

If Of the estimated 340,500 MBE children reported missing, 119,100 (35 percent) were youth who disclosed in the youth interview that their caretakers had contacted the police during an MBE episode. Because the youth interview questionnaire did not ask respondents why the police were contacted, researchers assumed that police were contacted in these 119,100 MBE cases to locate the missing child.

Caretakers of 39 percent of MILI children contacted the police or a missing children's agency, mostly for the purpose of locating the child (85 percent) (table 4). In 8 percent of these cases, the contact was to recover a child whose whereabouts had been identified in some other way, and in 8 percent, the contact was made for some other reason. Caretakers who did not contact the police explained most frequently that the episode did not last long enough to necessitate police involvement. By definition, the caretakers of all MBE children contacted the police. As with police contact in MILI cases, the police contact in $\mathrm{MBE}$ cases was mostly for the purpose of locating the child (91 percent). In 6 percent of $\mathrm{MBE}$ cases, the contact was to recover a child whose whereabouts had been identified in some other way, and in 3 percent, the contact was made for some other reason.

\section{Historical Trends}

The research team conducted a special comparative analysis of NISMART-1 and NISMART-2 data, using the most equivalent definitions and methodology to examine possible historical trends in various types of missing children episodes. ${ }^{4}$ This analysis found that, between 1988 and 1999, the incidence rate of children who experienced what NISMART-1 defined as a "lost, injured, or otherwise missing" episode declined (Hammer et al., 2004:6). (This NISMART-1 category included both MILI and MBE children; however, the exact definitions were somewhat different.) One possible explanation for the decline is the introduction and broad dissemination of new communications technologies, such as cell phones, car phones, and pagers, between 1988 and 1999. These 
devices have enabled family members, including children and youth, to contact each other more readily in exactly the types of situations that may have triggered alarm about a child being lost or missing in the past.

\section{Policy Implications}

Children missing involuntarily because they were lost, injured, or stranded and those missing for benign reasons constitute a substantial number of missing children who do not fall neatly into the more conventional categories of abducted, runaway, or thrownaway. In 1999, children missing for benign reasons constituted a major portion43 percent-of all missing children reported to the police, second only in size to those classified as runaway/ thrownaway. ${ }^{5}$ During the same year, an estimated 43,700 children were missing because they were injured. Yet interest in missing children has largely focused on those who have been abducted or have run away, and scant attention has been paid to children who become missing for other reasons.

Policymakers should recognize that children who become missing involuntarily because they are lost, injured, or stranded are a significant part of the overall missing children problem. MILI cases call for collaboration between law enforcement and a variety of other agencies, including the medical and public health community, forest rangers and game wardens, and other civil authorities. Agencies that respond to missing children cases should be prepared to respond in MILI cases, and responders should receive training in how to differentiate MILI episodes from other kinds of missing children episodes. MBE episodes are equivalent to mistakenly triggered burglar or fire alarms. Minimizing the amount of time and effort these situations demand from law enforcement should be an important policy goal. Public education on ways to avoid such mishaps and miscommunications and using successful search strategies for resolving such episodes may be helpful.

The most encouraging news is that the incidence of these episodes may have declined over the past decade, perhaps, in part, as a result of the introduction and dissemination of new communications technologies. Because keeping family members in touch with one another is an important outgrowth of new technologies, continued reductions in the number of children who become missing for preventable reasons may be expected. Moreover, technological advances in communications may also help reduce the number of children who become missing because they are lost, stranded, or have experienced a medical emergency.

\section{Endinotes}

1. The estimates provided here for the MILI category are marginally higher than estimates provided in a previous Bulletin, National Estimates of Missing Children: An Overview (Sedlak et al., 2002). The change resulted from the discovery of one child in the survey who had an experience that qualified as a MILI episode but who was inadvertently left out of that category because the child also had experienced another, separate missing child episode that came under a different category. The change does not affect the overall estimate of missing children.

\section{For Further Information}

This is the sixth Bulletin in the NISMART series and the fourth in the series to report NISMART-2 findings on specific categories of missing children. The other three series Bulletins that report findings from the NISMART component studies are Children Abducted by Family Members: National Estimates and Characteristics, Nonfamily Abducted Children: National Estimates and Characteristics, and Runaway/ Thrownaway Children: National Estimates and Characteristics. The first NISMART Bulletin, National Estimates of Missing Children: An Overview, describes the NISMART-2 component studies and estimating methodology, defines the types of episodes studied, and summarizes NISMART-2 estimates of missing children. The fifth Bulletin in the series, National Estimates of Missing Children: Selected Trends, 1988-1999, presents results of a special analysis comparing selected findings from NISMART-2 and its predecessor, NISMART-1.

NISMART Questions and Answers, a fact sheet, offers a straightforward introduction to NISMART-2. It answers anticipated questions - such as What is NISMART? Have abductions by strangers declined or increased? and Why can't I compare NISMART-1 statistics with NISMART-2 statistics?-to help explain NISMART's purpose, methodology, and findings.

AII NISMART-related publications are available at OJJDP's Web site, www.ojp.usdoj.gov/ojjdp. 


\section{NISMART}

2. One obvious limitation to the Household Surveys is that they may have undercounted children who experienced episodes but were living in households without telephones or were not living in households during the study period, including street children and homeless families. Although these are not large populations, they may be at risk for episodes.

3. The caretaker missing and reported missing estimates are close but not identical because caretaker MBEs required, by definition, a report to law enforcement or a missing children's agency for any reason, and 9 percent of these reports were for purposes other than to locate the missing child. Classification as "reported missing" required that the report to law enforcement or a missing children's agency be made for the purpose of locating the missing child.

4. Because of important differences in both definitions and methodology, the NISMART-1 and NISMART-2 data and findings should not be compared directly. For details about the comparison, see National Estimates of Missing Children: Selected Trends, 1988-1999 (Hammer et al., 2004).

5. For definitions of the NISMART-2 categories, see National Estimates of Missing Children: An Overview (Sedlak et al., 2002).

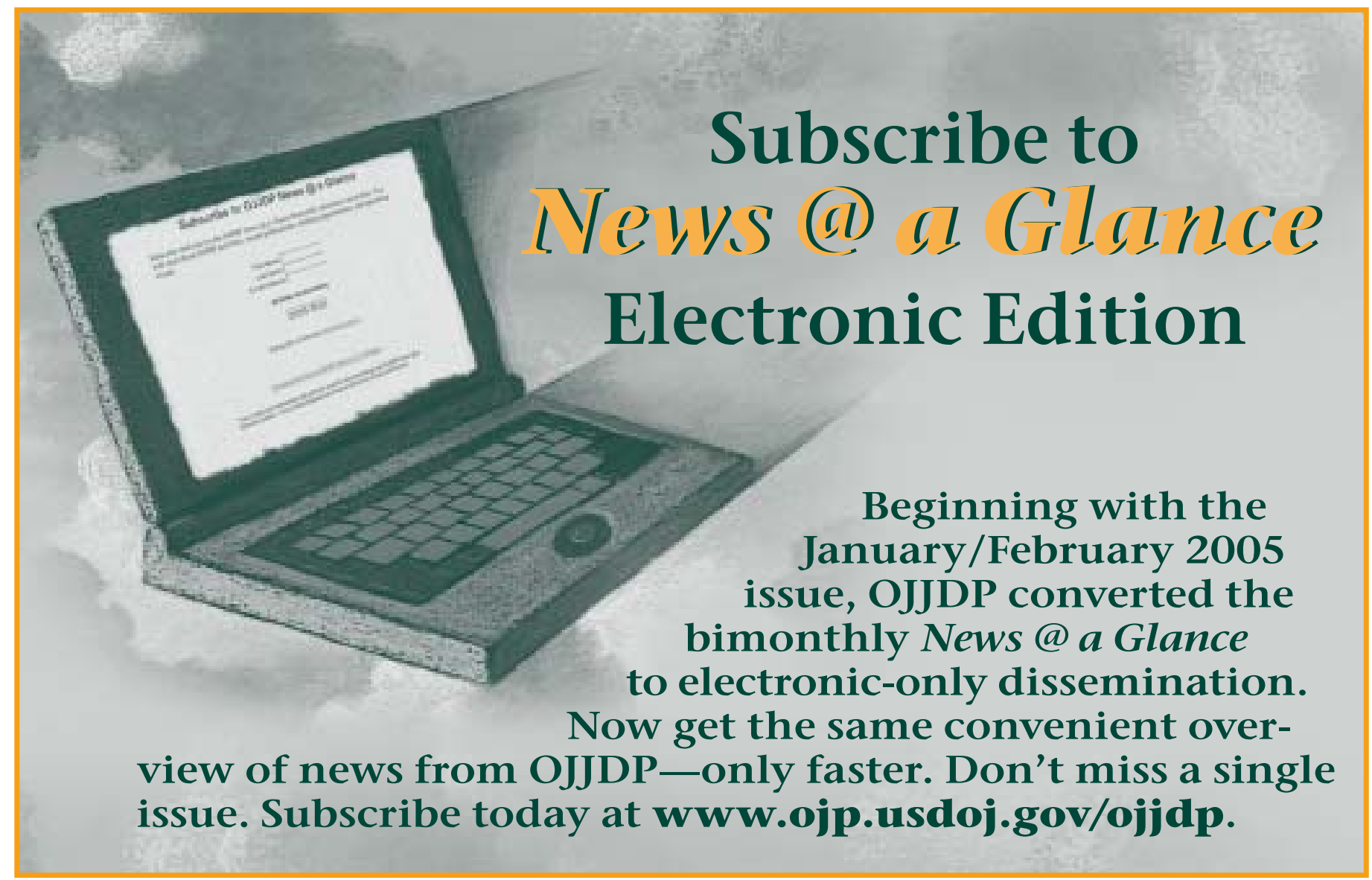




\section{References}

Finkelhor, D., Hotaling, G., and Sedlak, A. 1990. Missing, Abducted, Runaway, and Thrownaway Children in America. First Report: Numbers and CharacteristicsNational Incidence Studies. Washington, DC: U.S.

Department of Justice, Office of Justice Programs, Office of Juvenile Justice and Delinquency Prevention.

Hammer, H., Finkelhor, D., Sedlak, A.J., and Porcellini, L.E. 2004. National Estimates of Missing Children:

Selected Trends, 1988-1999. NISMART Bulletin. Washington, DC: U.S. Department of Justice, Office of Justice Programs, Office of Juvenile Justice and Delinquency Prevention.

Sedlak, A.J., Finkelhor, D., Hammer, H., and Schultz, D.J. 2002. National Estimates of Missing Children: An Overview. NISMART Bulletin. Washington, DC: U.S. Department of Justice, Office of Justice Programs, Office of Juvenile Justice and Delinquency Prevention.
U.S. Census Bureau. 2000a. Monthly Postcensal Resident Population, by Single Year of Age, Sex, Race, and Hispanic Origin (e9899rmp.txt, e9999rmp.txt, and e9900rmp.txt). Web site: eire.census.gov/popest/archives/ national/nat_90s_detail/nat_90s_1.php.

U.S. Census Bureau. 2000b. Population Estimates for the U.S. and States by Single Year of Age and Sex: July 1, 1999 (ST-99-10). Web site: eire.census.gov/popest/ archives/state/st-99-10.php.

This Bulletin was prepared under grant number 95-MC-CX-K004 from the Office of Juvenile Justice and Delinquency Prevention, U.S. Department of Justice, to Temple University.

Points of view or opinions expressed in this document are those of the authors and do not necessarily represent the official position or policies of OJJDP or the U.S. Department of Justice.

The Office of Juvenile Justice and Delinquency Prevention is a component of the Office of Justice Programs, which also includes the Bureau of Justice Assistance, the Bureau of Justice Statistics, the National Institute of Justice, and the Office for Victims of Crime.

\section{Acknowledgments}

Andrea J. Sedlak, Ph.D., is Associate Director of Human Services Research at Westat, Inc.; Project Director of the NISMART-2 Unified Estimate, Juvenile Facilities Study, and Law Enforcement Study; and Advisor to the NISMART-2 Household Survey. David Finkelhor, Ph.D., is Professor of Sociology and Director, Crimes against Children Research Center, University of New Hampshire, and Advisor to NISMART-2. Heather Hammer, Ph.D., is a Senior Study Director at the Temple University Institute for Survey Research, Philadelphia, PA, and Principal Investigator of NISMART-2.

Other contributors include Louise Hanson, M.A.S., Senior Project Director at Westat, Inc., and Director of Data Collection for the NISMART-2 Household Surveys; Michael K. Barr, M.A., Study Director at the Temple University Institute for Survey Research; Dana J. Schultz, M.P.P., Associate Policy Analyst, RAND Corporation, Pittsburgh, PA, Operations Manager of the Juvenile Facilities Study and Law Enforcement Study and Analyst for the Unified Estimate; Richard Ormrod, Ph.D., Research Professor of Geography at the University of New Hampshire Crimes against Children Research Center; G. Hussain Choudhry, M.Sc., Senior Methodologist, Statistics Canada, Ottawa, Ontario, Canada; Svetlana Ryaboy, M.S., Statistician at Westat, Inc.; Monica Basena, M.A., Analyst at Westat, Inc.; and Ying Long, M.S., Programmer at Westat, Inc.

The authors extend their appreciation to Barbara Allen-Hagen, Senior Social Science Analyst at OJJDP and NISMART-2 Program Manager, for her support and guidance in every phase of this project. The authors also thank the many individuals who responded to the NISMART-2 surveys for their cooperation and candor. 
U.S. Department of Justice

PRESORTED STANDARD

Office of Justice Programs

POSTAGE \& FEES PAID DOJ/OJJDP

Office of Juvenile Justice and Delinquency Prevention

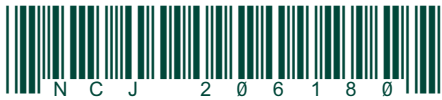

PERMIT NO. G-91

Washington, DC 20531

Official Business

Penalty for Private Use $\$ 300$ 